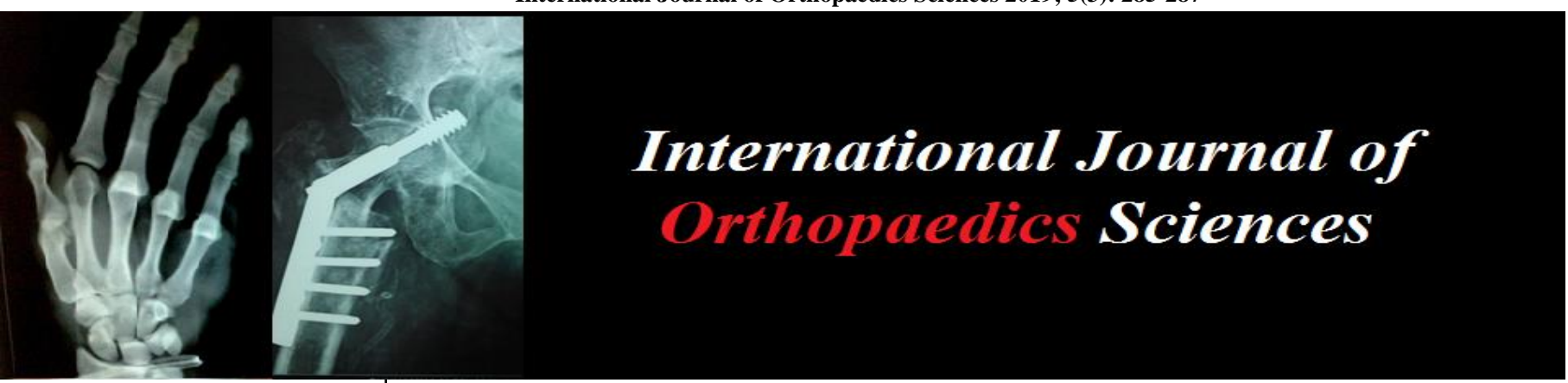

ISSN: $2395-1958$

IJOS 2019; 5(3): 285-287

(C) 2019 IJOS

www.orthopaper.com

Received: 16-05-2019

Accepted: 18-06-2019

Dr. Suresh Kumar Bhatnagar Assistant Professor, Department of Orthopaedic, American International Institute of Medical Sciences, Udaipur, Rajasthan, India

Dr. Mohammad Azmoddin Professor and HOD, Department of Orthopaedic, American International Institute of Medical Sciences, Udaipur, Rajasthan, India
Correspondence

Dr. Mohammad Azmoddin Professor and HOD, Department of Orthopaedic, American International Institute of Medical Sciences, Udaipur, Rajasthan, India

\section{Evaluation of efficacy of dynamic hip screw and proximal femoral nail in the treatment of intertrochanteric fractures of femur}

\author{
Dr. Suresh Kumar Bhatnagar and Dr. Mohammad Azmoddin
}

DOI: https://doi.org/10.22271/ortho.2019.v5.i3e.1541

\section{Abstract}

Background: Hip fractures include mainly trochanteric and femoral neck fractures. The dynamic hip screw (DHS), commonly used in extra medullary fixation, has become a standard implant in treatment of these fractures. Proximal femoral nail (PFN) and Gamma nail are 2 commonly used devices in the intramedullary fixation. Hence; the present study was planned for evaluating and comparing efficacy of dynamic hip screw and proximal femoral nail in the treatment of intertrochanteric fractures of femur.

Materials and Methods: A total of 20 patients scheduled to undergo treatment for intertrochanteric fractures of femur were included in the present study. All the patients were broadly divided into two study groups with 10 patients in each group. Group1 included patients who underwent treatment with DHS, while Group 2 included patients who underwent treatment with PFN. All the procedures were performed under the hands of skilled and experienced orthopedic surgeons. Postoperative follow-up records were maintained till one year time.

Results: No significant difference was obtained while comparing the complete union cases in between PFN group and DHS group. Significant results obtained while comparing the mean duration of surgery in between the subjects of the DHS group and the PFN group (P- value < 0.05). Mean duration of hospital stay in the patients of DHS group and PFN group were found to be 13.45 and 13 days respectively. Nonsignificant results were obtained while comparing mean duration of hospital stay in between the subjects of the DHS group and PFN group.

Conclusion: PFN is significantly better in comparison to DHS. However; further studies are recommended.

Keywords: Dynamic hip screw, femur, proximal femoral nail

\section{Introduction}

Hip fractures include mainly trochanteric and femoral neck fractures, and the former was reported with a mortality rate ranging from $15 \%$ to $30 \%$ in America. Surgical treatment with stable fixation allows early mobilization and reduces complications. There are two main types of fixations for trochanteric fractures, which are plate fixation and intramedullary implants ${ }^{\text {[1- }}$ 3]. The dynamic hip screw (DHS), commonly used in extra medullary fixation, has become a standard implant in treatment of these fractures. Proximal femoral nail (PFN) and Gamma nail are 2 commonly used devices in the intramedullary fixation ${ }^{[4,5]}$. Hence; under the light of above mentioned data, the present study was planned for evaluating and comparing efficacy of dynamic hip screw and proximal femoral nail in the treatment of intertrochanteric fractures of femur.

\section{Materials and Methods}

The present research was planned and conducted in the Department of Orthopaedics, American International Institute of Medical Sciences, Udaipur, Rajasthan, India and it included evaluation and comparison of efficacy of dynamic hip screw and proximal femoral nail in the treatment of intertrochanteric fractures of femur. Ethical approval was obtained from institutional ethical committee and written consent was obtained from all the patients after explaining in detail the entire research protocol. A total of 20 patients scheduled to undergo treatment for intertrochanteric fractures of femur were included in the present study. 
All the patients were broadly divided into two study groups with 10 patients in each group. Group1 included patients who underwent treatment with DHS, while Group 2 included patients who underwent treatment with PFN. All the procedures were performed under the hands of skilled and experienced orthopedic surgeons. Hematological and biochemical profile of all the patients was obtained before the starting of the treatment. Postoperative follow-up records were maintained till one year time. Radiographic union was also compared in between the two study groups at different time intervals. All the results were recorded in Microsoft excel sheet and were analyzed by SPSS software. Chi- square test was used for assessment of level of significance.

\section{Results}

In the present study, a total of 20 patients were analysed. Mean age of the patients of the present study. Majority of the patients belonged to the age group of more than 50 years. There were 6 females and 4 males among group 1 while there were 5 males and 5 females among group.

In the present study, among the subjects of the DHS group, in 6 patients $(60 \%)$, complete union occurred in 10 to 14 weeks' time, while in 4 patients $(40 \%)$, complete union occurred in 14 to 18 weeks' time. Among the subjects of the PFN group, in 7 patients $(70 \%)$, and 3 patients $(30 \%)$, complete union occurred in 10 to 14 weeks and 14 weeks to 18 weeks' time respectively. No significant difference was obtained while comparing the complete union cases in between PFN group and DHS group ( $\mathrm{P}$ - value $>0.05)$.

In the present study, mean duration of surgery in the patients of DHS group and the PFN group were found to be 65.12 and 55.36 minutes respectively. Significant results obtained while comparing the mean duration of surgery in between the subjects of the DHS group and the PFN group (P- value < 0.05). Mean duration of hospital stay in the patients of DHS group and PFN group were found to be 13.45 and 13 days respectively. Non- significant results were obtained while comparing mean duration of hospital stay in between the subjects of the DHS group and PFN group (P- value $>0.05$ ).

\section{Discussion}

Trochanteric femoral fractures are often seen in patients aged $>65$ years; they can be caused by high-energy or low-energy trauma or may be pathological in nature. Particularly in the elderly, hip fractures are a major cause of increased mortality and morbidity. ${ }^{5}$ Because of the decreased physical capacity, concomitant systemic diseases, and increased vulnerability to environmental dangers, even low-energy trauma can cause unstable femoral trochanteric fractures in this age group. ${ }^{6,7}$ Surgical management of hip fractures is targeted to help patients recover to the closest degree of functionality they had prior to the trauma; this is achieved by utilizing the most appropriate treatment methods and early ambulation, thereby preventing potential complications ${ }^{[8,9]}$.

In the present study, a total of 20 patients were analysed. Mean age of the patients of the present study. Majority of the patients belonged to the age group of more than 50 years. There were 6 females and 4 males among group 1 while there were 5 males and 5 females among group. In the present study, among the subjects of the DHS group, in 6 patients $(60 \%)$, complete union occurred in 10 to 14 weeks' time, while in 4 patients (40\%), complete union occurred in 14 to 18 weeks' time. Among the subjects of the PFN group, in 7 patients $(70 \%)$, and 3 patients $(30 \%)$, complete union occurred in 10 to 14 weeks and 14 weeks to 18 weeks' time respectively. No significant difference was obtained while comparing the complete union cases in between PFN group and DHS group ( $\mathrm{P}$ - value $>0.05)$. Zhang $\mathrm{K}$ et al. compared the outcomes of proximal femoral nail (PFN) and dynamic hip screw (DHS) in treatment of intertrochanteric fractures. Relevant randomized or quasi-randomized controlled studies comparing the effects of PFN and DHS were searched for following the requirements of the Cochrane Library Handbook. Six eligible studies involving 669 fractures were included. Their methodological quality was assessed and data were extracted independently for meta-analysis. The results showed that the PFN group had significantly less operative time, intraoperative blood loss, and length of incision than the DHS group. No significant differences were found between the 2 groups regarding postoperative infection rate, lag screw cut-out rate, or reoperation rate. The current evidence indicated that PFN may be a better choice than DHS in the treatment of intertrochanteric fractures ${ }^{[10]}$.

In the present study, mean duration of surgery in the patients of DHS group and the PFN group were found to be 65.12 and 55.36 minutes respectively. Significant results obtained while comparing the mean duration of surgery in between the subjects of the DHS group and the PFN group (P- value < 0.05). Mean duration of hospital stay in the patients of DHS group and PFN group were found to be 13.45 and 13 days respectively. Non- significant results were obtained while comparing mean duration of hospital stay in between the subjects of the DHS group and PFN group (P- value $>0.05$ ). Avakian $\mathrm{Z}$ et al. undertook a retrospective audit of 144 patients who received a dynamic hip screw or a proximal femoral nail in order to compare age, sex, duration of surgery, duration of hospitalization, time of first mobilization, and rate anaemia, sepsis, avascular necrosis, prosthesis failure, revision, deep vein thrombosis, pulmonary embolus, non-ST elevation myocardial infarction, common peroneal nerve palsy and death between implantation of a DHS and a PFN. No differences were found between groups in age, duration of surgery, duration of hospitalization, time of first mobilization and rate of complications. Statistically significant differences were found in sex distributions, operation time and length of stay. However, analysis of median operation time and length of stay when adjusted for sex revealed no significant differences. Their study demonstrated no statistically significant differences in peri- and post-operative measures between patients undergoing intertrochanteric fracture fixation via PFN or DHS [11]

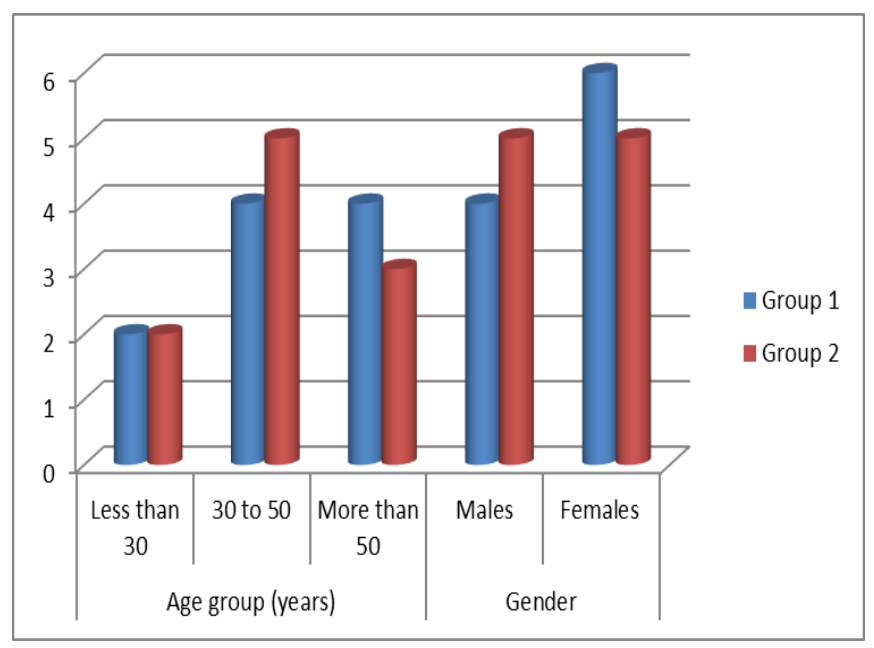

Graph 1: Demographic datal 
Table 1: Distribution of subjects with complete radiological union according to different time

\begin{tabular}{|c|c|c|c|c|c|}
\hline \multirow{2}{*}{ Duration } & \multicolumn{2}{|c|}{ Group 1 } & \multicolumn{2}{c|}{ Group 2 } & \multirow{2}{*}{ p- value } \\
\cline { 2 - 5 } & Number & Percentage & Number & Percentage & \\
\hline 10-14 Weeks & 6 & 60 & 7 & 70 & \multirow{2}{*}{0.45} \\
\hline 14-18 Weeks & 4 & 40 & 3 & 30 & \\
\hline Total & 10 & 100 & 10 & 100 & \\
\hline
\end{tabular}

Table 2: Comparison of mean duration of surgery in between the DHS group and PFN group

\begin{tabular}{|c|c|c|c|}
\hline Group & Duration of surgery & SD & P-value \\
\hline Group 1 & 65.12 & 4.88 & \multirow{2}{*}{0.000} \\
\hline Group 2 & 55.36 & 5.98 & \\
\hline
\end{tabular}

Table 3: Comparison of mean hospital stay in between DHS group and PFN group

\begin{tabular}{|c|c|c|c|}
\hline Group & Hospital stay & SD & P-value \\
\hline Group 1 & 13.45 & 2.87 & \multirow{2}{*}{0.45} \\
\hline Group 2 & 13 & 2.11 & \\
\hline
\end{tabular}

\section{Conclusion}

Under the light of above mentioned data, the authors conclude that PFN is significantly better in comparison to DHS. However; further studies are recommended.

\section{Reference}

1. Cummings SR, Rubin SM, Black D. The future of hip fractures in the United States. Numbers, costs, and potential effects of postmenopausal estrogen. Clin Orthop Relat Res. 1990; 252:163-66.

2. Kannus P, Parkkari J, Sievänen $\mathrm{H}$ et al. Epidemiology of hip fractures. Bone. 1996; 18(Suppl 1):57-63.

3. Bridle SH, Patel AD, Bircher M, Calvert PT. Fixation of intertrochanteric fractures of the femur. A randomized prospective comparison of the gamma nail and the dynamic hip screw. J Bone Joint Surg Br. 1991; 73(2):330-34.

4. Radford PJ, Needoff M, Webb JK. Aprospective randomised comparison of the dynamic hip screw and the gamma locking nail. J Bone Joint Surg Br. 1993; 75(5):789-93.

5. Goldhagen PR, O'Connor DR, Schwarze D, Schwartz E. A prospective comparative study of the compression hip screw and the gamma nail. Journal of Orthopaedic Trauma. 1994; 8(5):367-372.

6. Hoffman CW, Lynskey TG. Intertrochanteric fractures of the femur: a randomized prospective comparison of the gamma nail and the ambi hip screw. Australian and New Zealand Journal of Surgery. 1996; 66(3):151-155.

7. Radford PJ, Needoff M, Webb JK. A prospective randomised comparison of the dynamic hip screw and the gamma locking nail. Journal of Bone and Joint Surgery B. 1993; 75(5):789-793.

8. Parker MJ, Handoll HH. Gamma and other cephalocondylic intramedullary nails versus extramedullary implants for extracapsular hip fractures in adults. Cochrane Database of Systematic Reviews. 2010; 16(3):CD000093.

9. Butt MS, Krikler SJ, Nafie S, Ali MS. Comparison of dynamic hip screw and gamma nail: a prospective, randomized, controlled trial. Injury. 1995; 9:615-18.

10. Zhang K, Zhang S, Yang J et al. Proximal femoral nail vs. dynamic hip screw in treatment of intertrochanteric fractures: a meta-analysis. Med Sci Monit. 2014; 20:1628-1633. Published 2014 Sep 12.
doi:10.12659/MSM.890962

11. Avakian Z1, Shiraev T, Lam L, Hope N. Dynamic hip screws versus proximal femoral nails for intertrochanteric fractures. ANZ J Surg. 2012 Jan-Feb;82(1-2):56-9. doi: 10.1111/j.1445-2197.2011.05929.x. Epub 2011 Dec 15. 